much smaller, indicating the existence of a still more penetrating type of radiation than the $\gamma$, but our preparations are hardly sufficiently active to enable us to establish this beyond doubt. Here again the experiments we propose with the radium $\gamma$ rays may throw more light on the matter.

FREDERICK SODDY.

ALEXANDER S. Russell.

Physical Chemistry Laboratory, University of Glasgow, February 27 .

\section{The Radio-active Deposits from Actinium.}

In NATURE of February 25 there appeared a letter from Prof. McLennan containing the results of some experiments recently made by Mr. W. T. Kennedy on the behaviour of the active deposit from actinium emanation.

So far as may be judged from the details given of the observations, they substantially confirm the results obtained by the writer, which are to be found in the Phil. Mag., May and June, 1908.

The suggestion that the differences in the quantity of active deposit observed on the positive and negative electrodes can be explained by the different rates of diffusion of the ions is an interesting one, but it seems likely that the determining factor is the frequency of collision between the active deposit particles and the gas molecules or ions with which they are mixed.

It is impossible to make a complete comparison between the experiments of $\mathrm{Mr}$. Kennedy and myself until further data are available.

Physical Laboratories, Manchester University.

\section{The Production of Prolonged Apncea in Man.}

Noticing the letter by Dr. H. M. Vernon in Nature of February 18 on "The Production of Prolonged Apnœea in Man" it recalled to my mind some observations on the same subject communicated to the Philosophical Magazine in 1833, vol. iii., p. 241, by Michael Faraday, and reprinted in his collected "Researches in Chemistry and Physics," pp. 358-62.

The effect of a bout of forced breathing in enabling a person greatly to prolong the time during which they can hold their breath was brought under the notice of Faraday by Sir Graves C. Haughton.

Faraday was ever one who put things to a practical use, and he gives directions as to the mode of proceeding when one had to enter a noxious atmosphere to rescue a person overcome by the fumes of a poisonous gas. $\mathrm{He}$ says:- "Avoid all unnecessary action; for activity exhausts the air in the lungs of its vital principle more quickly, and charges it with bad matter. Go collectedly, coolly, and quietly to the spot where help is required: do no more than is needful, leaving what can be done by those who are in a safe atmosphere (as the hauling up of a senseless body, for example) for them to do.

"Take the precautions usual in cases of danger in addition to the one now recommended [namely, by preparing the lungs by several deep breaths]. Thus, in a case of choke-damp, as in a brewer's vat, hold the head as high as may be; in a case of fire in a room, keep it as low down as possible."

$\mathrm{He}$ concludes his communication with a remark on the effect of increasing the pressure of the air breathed by giving the case in which Mr. Brunel, jun., descended in a diving-bell to a depth of 30 feet below the surface of the water, when it was found that both he and his companion could remain under water (by descending from the bell itself) for about twice as long as they could had the air they breathed only been under normal pressure. It would be interesting to know how long the breath could have been held in the above case had Mr. Brunel employed forced breathing, supplemented by three or four breaths of pure oxygen. If the relation of pressure and time during which the breath could be retained held good for the time of $8 \mathrm{~m}$. r3s. given by $\mathrm{Mr}$. Vernon, this period should be increased to $16 \mathrm{~m}$. $26 \mathrm{~s}$. when air under two atmoNO. 2053 , VOL. 8o] spheres (absolute) pressure was breathed, aided by about four breaths of oxygen. W. G. Royal-Dawson. 40 Creffield Road, Ealing, February 23.

\section{A Winter Retreat.}

Mr. George Gilibert, a market-gardener in Stonehaven, has shown me a curious phenomenon which I have not met with before, and which, I think, deserves to be recorded. About the beginning of November a number of children were playing at a tea-party, and they left among the herbaceous plants at the side of the walk an earthenware tea-pot, the dimensions of which were 4 inches by 3 inches. A few days ago the old tea-pot was discovered lying on its side and without a lid. In the interior, closely packed, were no fewer than thirty-seven of the common garden shelled-snail, and when ejected they were found to be all alive. They had spent the months in their winter retreat. Probably gardeners know that they can trap snails in some such way; at all events, one often finds snails in confined spaces and sheltered nooks. Still, the question arises, What led one mollusc to follow the others? Is it the sense of smell? What attracted no fewer than thirty-seven to this old tea-pot, probably a very snug and safe place? Still, there is a danger in being in a crowd. One can imagine how delighted a sea-gull would have beers to have discovered this larder of fresh meat! JoHn G. MCKENDRICK.

\section{Priestley and Coulomb's Law.}

IN our text-books on electricity I do not remember to have seen Priestley's name associated with the proof of Coulomb's law as derived from the fact that no electrification can be obtained in the interior of a sphere charged with electricity.

In the article "Priestley" in the "Dictionary of National Biography " it is stated that Priestley anticipated Coulomb's law, and in looking into the matter I find foundation for the statement in the following paragraph from "The History and Present State of Electricity with Original Experiments," by Joseph Priestley, second edition,

1769 , p. 711:electrification within an electrified cup) "that the attraction of electricity is subject to the same laws with that of gravitation and is therefore according to the squares of the distances; since it is easily demonstrated that were the earth in the form of a shell a body in the inside of it would not be attracted to one side of it more than another."

Birmingham, February 26.

C. J. WOODWARD.

\section{Barometric Oscillation.}

IN my remark referred to by Mr. Braak (February I8, p. 459) I merely meant the increase of temperature which inevitably occurs when a gas is compressed. The compression and warming are simultaneous; this is shown in the passage of a sound wave where the air is compressed and warmed, and expanded and cooled alternately many hundreds of times in a second. If a barometric change is followed by a change of temperature at some subsequent time the result must be due to other conditions than those to which I alluded.

W. H. Dines.

\section{Life and Letters of Prof. A. Newton, F.R.S.}

I HAVE been invited to write a life of the late Prof. Alfred Newton, F.R.S., of Magdalene College, Cambridge. If any of your readers who have letters or reminiscences or other interesting information about Prof. Newton will be kind enough to communicate with me, I shall be exceedingly grateful to them. I will, of course, undertake to return all letters, \&c., to the senders.

Savile Club, ro7 Piccadilly, W., March $\mathrm{I}$. 